\title{
11
}

\section{Contemporary developments in political space in France}

\author{
Robert Andersen \\ and \\ Jocelyn A. J. Evans
}

\section{Introduction}

The emphasis of the book thus far has been on individual parties and coalitions. Nonetheless, the demand side of the equation also provides an important context to party success because it helps define the political space in which parties must compete for voters. In this chapter, then, we focus on French political space over the last fifteen years as defined by the socio-demographic and attitudinal profiles of the voters. We build upon findings from the two major studies of French voters in the last ten years, namely L'électeur français en questions (Boy and Mayer, 1990) ${ }^{1}$ and L'électeur a ses raisons (Boy and Mayer, 1997).

The first of these studies was based upon SOFRES data from the 1988 presidential post-election survey and depicted the French electorate as occupying a bidimensional space defined by economic liberalism - state intervention versus laissez-faire - and cultural liberalism - libertarian versus authoritarian - axes. The latter used the 1995 presidential survey to update the analysis and presented a new model of political space at the electoral level - a tripartition into left, moderate-right and extreme-right political blocs - representing a radical departure from the traditional quadrille bipolaire, and exploding the bidimensional account into a series of cultural subdimensions. Employing these two datasets, together with the CEVIPOF legislative post-election survey from 1997 to update the analysis, we consider changes in the social and attitudinal determinants of political space since 1988. Our analysis takes into account the two principal partisan developments during this period - the growth and implantation of the FN and the more recent establishment of the gauche 
plurielle governing coalition - to assess the extent to which change took place during this period.

\section{Traditional political space in France}

Until recently, most research has found the left-right political spectrum and its underlying social bases to provide an enduring and simple map of political space in France. The French political landscape had been firmly implanted along the dual cleavages of social class and religion since the nineteenth century, producing strong left-right polarisation. In keeping with the general pattern found in predominantly Catholic countries, left voting had traditionally been broader than just the working-class, encompassing a secular and often overtly anti-clerical component composed of public sector employees and educators. Thus, the French left had always played host to a middle-class voter with a socially liberal value system focused upon individual equality and enlightened rationalism, as well as to the lower-class voter concerned more with economic equality and state-controlled protectionism.

For its part, the right bloc had traditionally been dominated by the Catholic conservative middle class composed of the traditional petty bourgeoisie (i.e., farmers, craftsmen, traders, owners of small businesses), professionals, and the upper salariat. Supporters of the right bloc could be further divided into those who were economically liberal and socially conservative, and those who were economically liberal but less socially conservative. The former characterised the petty bourgeoisie who shunned leftist collectivism and upheld the Catholic conservative value-system that promoted hierarchy and order (Mayer, 1983). The petty bourgeoisie also favoured economically liberal policies that provided tax incentives for small businesses and prevent excessive market regulation. Professionals and the upper salariat constituted the other group, typically being more socially liberal and owing as much to the liberal tradition characteristic of Northern Europe as to any Catholic doctrine.

Few challenged this basic designation of the French political landscape along social and religious cleavages. Sometimes mediated by the institutional framework or anti-system cleavages - for instance the pragmatic alliance of the centre characteristic of the Third and Fourth Republics or the anti-Gaullist cleavage of the early Fifth Republic - the left-right dichotomy and its economic and cultural subdimensions truly emerged as the effective predictor of voting choice by the 1980s (Capdevielle et al., 1981, Bartolini 1984). Nuances of patrimoine and religious practice and the recently more complicated class structure aside, even the basic working class and Catholic labels remained largely synonymous with left and right bloc belonging respectively. 
Although the extent of its predictive power has somewhat declined in recent years, left-right ideology still remains of paramount importance. The post-industrial shifts in the 1970s and 1980s which threatened the status quo with radical re/dealignment has in fact settled into a more nuanced but structurally similar competitive framework. ${ }^{2}$ Even new issues, such as post-materialism, have easily been absorbed in France as elsewhere into the bidimensional economic and cultural liberalism foundations to left-right orientation (Kitschelt and Hellemans, 1990, Grunberg and Schweisguth, 1993, Knutsen, 1995). Moreover, parties mobilising around these issues, such as the Greens, have been integrated into the principal left-right axis of competition.

As Ivaldi has already alluded to, in recent years the extreme right of Jean-Marie Le Pen and the FN has posed a challenge to the effectiveness of this traditional map. Although conventionally seen as the radical wing of the right bloc, a number of elements to the FN's electoral and ideological profile do not conform to the traditional left-right map (Perrineau, 1997: 208-26, Mayer, 1999: 214-22). In particular, recent shifts in economic policy and the presence of a large number of working-class voters in the extreme-right electorate have suggested that the party no longer sits comfortably on the margins of the right. ${ }^{3}$ Some have seen this as simply the manifestation of a protest movement with a pragmatic, reactive approach to economic policy or a populist party drawing support from all parts of the political spectrum. Gérard Grunberg and Etienne Schweisguth's influential analysis of public opinion in 1995 in L'électeur a ses raisons, however, suggests that a combination of shifts in the social bases of extreme-right support and significant changes in the electorate's values has resulted in the FN separating from the moderate right and consequently becoming a political orientation sui generis - the so-called tripartition of political space into left, moderate-right and extreme-right blocs (Grunberg and Schweisguth, 1997).

An implication of the tripartition thesis is that the left does not merit a similar separation into extreme and moderate blocs. At first glance, this bears out when we examine the second shift in the party landscape, namely the appearance of the gauche plurielle. Paradoxically, this change seems to have consolidated the left side of the spectrum to an extent not seen before under the Fifth Republic. Such convergence suggests that an emphasis on pluralism of views being brought into the governing fold may be matched by a convergence of mass attitudes to an extent to allow this, in contrast with the fortunes of past left alliances. Put another way, a cohesive plural left cannot afford to be too plural at either mass or elite levels. We turn to look at this aspect now, before considering the tripartition hypothesis in more detail. 


\section{The consolidation of the gauche plurielle}

As Hanley's chapter has shown (Chapter 5, this volume), left-wing parties have always engaged in various kinds of within-bloc alliance, although until the 1990s, these have proved for the most part fragile and short-lived. The Rocard minority government's equally doomed overtures to the centre CDS in 1988 fell prey to the inescapable logic of the bipolar blocs of left and right which the Fifth Republic's institutional and electoral framework had established. Conversely, the gauche plurielle has been much more stable than many commentators had foreseen, bringing together a PCF which had previously helped bring down the first PS-dominated government, a vocal Green Party previously unrepresented in government and a fiercely Jacobin $\mathrm{MdC}$ with an Interior Minister, Jean-Pierre Chevènement, who had resigned from the previous left government over the Gulf War. ${ }^{4}$

As Hanley suggests, this stability has been based firstly on the weakness of the PS and the need for its elites to compromise; and second, upon its minor partners' need of the coalition in order to enter government. The emphasis here is clearly on elite pragmatism. What has not yet been analysed is the extent to which it is matched by, if not predicated upon, a growing convergence within the left-wing electorate. The Greens of the Waechterian period placed great emphasis on the salience of Green issues, and eschewed the mainstream policy alternatives which threatened to render them a party comme les autres. Such isolated electoral success has not been matched, but the integrated 'realistic' Green strategy epitomised by Dominique Voynet has come close, and better still has brought the Greens into the incumbent fold. If for the Green vote the environment retains primacy in issues terms, mainstream left-wing economic and social considerations have also risen in importance.

Similarly, the reactionary idealism that returned the PCF to the wilderness in the mid-1980s has been replaced by a more pragmatic 'liberal' programme capable of attracting and accepting a half non-communist and grudgingly pro-European list in the European elections of 1999, the edicts of democratic centralism a thing of the past. Furthermore, its electoral results may be a long way below those of its anti-system heyday, but the terminal collapse predicted since the Eastern bloc cataclysm of 1989/90 and reiterated on a regular basis since had failed to materialise by 1997 (although came a step closer after the 2002 results). Given the presence of the gauche de gauche LO and just as importantly the plethora of non-electoral social movements highlighted by Wolfreys in Chapter 6 , less entrenched sections of the PCF electorate displeased with the ideological bent of Hue's party could certainly find alternative vote receptacles or modes of political action. 
Many commentators have emphasised that the party grouping of the left is solely pragmatic. They argue that it merely represents a declining PS shoring up its electoral success in 1997 with Green, PCF and MdC supporters. In return, these parties used the opportunity as a ticket out of the electoral wilderness without relinquishing their old identities. ${ }^{5}$ Similarly, Villalba and Vieillard-Coffre have underlined in Chapter 4 of this volume that the factions vying for power and the presidential candidacy within the Greens have disagreed over the extent to which the PS had betrayed the former's demands made as a condition of their governmental support. We know of no analysis concentrating on the ideological consistency of the core electorates supporting this alliance, however. Data from 1988-97 are important because they can indicate whether the electorates were in the process of converging before the 1997 governing coalition. These data can also give hints to what extent the compromises of five years in government were challenged in the 2002 elections because of a priori dissatisfaction with ideological incompatibility. Future data on the 2002 elections will be crucial in determining whether the period of the gauche plurielle's first incumbency resulted in convergence of the respective parties' voters. However, given the results of the 2002 legislative elections, it must be said that, if any convergence did occur after 1997, it had absolutely no cohesive effect on the left.

Thus, in looking at the success of the left bloc, we will explore whether there was a homogenisation of its electorate in attitudinal terms. This homogenisation, then, should reflect growing cultural liberalisation of the French electorate (Schweisguth, 2000) and the declining impact of the previously explosive topic of economic management. As a mirror image to this process, however, the second major partisan development of relevance to this analysis has been seen as fragmenting rather than uniting the right bloc.

\section{Tripartition and the fragmentation of the right}

The tripartition argument implies that the extreme right now possesses a basis for long-term stable identification. In other words, the social and ideological characteristics of its electorate should be quite distinct from the two traditional political blocs. This would, of course, give less credence to the protest and populist arguments since it implies that the basis of FN support is not solely due to socially segmented interests or the popularity of its leader.

The rise of the anti-system $\mathrm{FN}$ during the 1980s did not initially challenge the stability of left-right politics because it was perceived to be in proximity to its moderate-right neighbours, at least during its early years. Its early espousal of neo-liberal economic doctrine, together with 
an authoritarian moral and overtly anti-immigrant line placed it firmly in the right bloc. Yet by 1995, the FN's traditional petty bourgeois Catholic support had been increasingly matched by working-class and secular voters with economically more interventionist views more characteristic of the left-wing parties from which many had come. Thus, Charlot's 'double electorate' of 1988 had become implanted (Charlot, 1988: 30), apparently unified only in their socially conservative and ethnocentric views, but also, in keeping with the extreme-right trends across Europe, manifesting decreasing levels of education and being drawn increasingly from younger cohorts (Betz, 2001). In social terms too, then, the extreme-right voter decreasingly resembled his older, more educated moderate-right counterpart.

For Grunberg and Schweisguth, the change in profile of extreme-right voters reflected a reorientation of ideological concerns on the extreme right, and in particular a decline in importance of economic liberalism and the fragmenting of attitudes pertaining to the previously unidimensional cultural liberalism scale. In the case of economic liberalism, the decline in state intervention as a policy option and indeed its failure under the Socialists during the 1980s has led the left to move away from its previous position of protectionism and engage in its own privatisations (Grunberg and Schweisguth, 1997: 148). Paradoxically, the FN has moved towards the left, abandoning radical neo-liberalism and adopting a more mixed protectionist policy offering national preference in response to the demands of its disenchanted working-class voters who precisely wish to benefit from some element of economic and social protectionism. Moreover, the moderate right cannot be said to promote unfettered neo-liberal economic policies during this period either. ${ }^{6}$

In contrast to the convergence of bloc supporters in terms of economic attitudes, Grunberg and Schweisguth posit a more striking evolution in cultural liberalism. Although historically conceived of as a single ideological dimension, they argue that 1988 saw it explode into a number of independent subdimensions. In particular, they argue that by 1995 issues related to homosexuality, the death penalty and immigration could no longer be used to map French parties along a single cultural liberalism scale. They argue that cultural liberalism should now seen as two separate fundamental value sets: progressive-traditional and socially egalitarianhierarchical elements. The latter of these they also refer to as the universalist-anti-universalist dimension (1997: 164). The former is closely linked to religiosity, being the ideological manifestation of the secularCatholic conflict over attitudes on moral matters, such as homosexuality and abortion. While the extreme right had manifested a strong element of moral authority in 1988, by 1995 these issues had become the domain of the moderate-right identifiers, whereas attitudes to social authority and law and order, as well as differentiation and rejection of out-groups 
had intensified on the part of the extreme right. In the same way that the moral elements were characterised by high levels of religiosity, so the authoritarian and ethnocentric elements forming the anti-universalist belief system were characterised by low levels of education (1997: 168).

Thus, if Grunberg and Schweisguth are correct, a younger, more secular, less educated group of anti-universalist extreme-right voters should now be separated from the older, religious, educated traditionalists of the moderate right. This profile matches the modernisation loser or populist models of extreme-right support (Betz, 1994, Minkenberg, 1998). Grunberg and Schweisguth lay particular emphasis on the separation of political blocs, the extreme-right bloc in their formulation being in many ways as close to their left-wing counterparts as to the moderate right, at least in social structural terms. The key difference lies in the ideology, however, which as we have noted has moved in the opposite direction from the general trend in the French population towards greater cultural liberalism.

\section{Expanding Grunberg and Schweisguth's analysis}

Grunberg and Schweisguth base their findings on the SOFRES presidential surveys, using presidential vote to define political space. Such a measure of political space can be problematic because it does not take into account the various important pragmatic or non-ideological considerations which may motivate a voter's presidential choice - credibility, personality effects, economic considerations, protest, inter alia. Instead, party proximity or party identification are more suitable measures of political space because they imply a longer term psychological attachment more appropriate for defining political bloc identification. In addition the inclusion of the 1997 data, which were not available when Grunberg and Schweisguth carried out their analysis, means that the only constant variable in voting terms is that of identification - all legislative voting in the presidential surveys is recalled at two years' distance. We thus use the identification measure as our dependent variable, rather than presidential vote. ${ }^{7}$

To look at the shifts in political space, rather than the individual ideologies of party electorates, we group the parties into the three relevant blocs for the analysis. Mean scores and distributions of the socio-demographic indicators and attitudinal data will indicate the relative distance between the three blocs - of importance to the definition of the dimensions in political space. As concerns the homogeneity of the left bloc, standard deviations of the attitudinal items will indicate the trends in this across time. Bloc allocation of the parties is given below (Table 11.1).

As independent variables, we look first at the social indicators of bloc 
TABLE 11.1 Allocation of party proximity response to blocs

\begin{tabular}{llll}
\hline & Left & Moderate right & Extreme right \\
\hline 1988 & Extreme left & UDF & FN \\
& PCF & RPR & \\
& PS & & \\
& Left-Radicals & & \\
& Ecology parties & & \multirow{2}{*}{ FN } \\
& Extreme left & UDF & \\
PCF & RPR & \\
PS & MPF & \\
& Left-Radicals & & \\
& 'Ecology Generation' & & FN \\
& Greens & & \\
Extreme left & UDF & \\
& PCF & RPR & \\
& PS & MPF & \\
\hline
\end{tabular}

belonging - age, gender, education, class and religion - and then look at the bloc positions on economic liberalism dimension, as manifested by a question on respondents' attitudes to privatisation; cultural liberalism, using support for or rejection of re-establishing the death penalty; and ethnocentrism, using a question on respondents' views on the number of immigrants in France being excessive. Lastly, because of its importance in the tripartition argument, we include the 1988 and 1995 data for homosexuality, the item unfortunately being missing in 1997.

Including 1997 in the analysis is important both because it provides a longer time period over which to assess trends and also for a number of contextual reasons. First, party actors remained stable from 1995, and the principal shift in voting alignment occurred between moderate left and moderate right, together with the reintegration of abstainers and generational turnover favouring the left. Indeed, the extreme right consolidated its position, with the FN winning just below what Le Pen received in the 1995 elections - 15 per cent as compared with 15.5 per cent. This was the first time that the legislative score had so closely approached the presidential equivalent. Furthermore, in 1997 the number of extreme-right identifiers jumped to 7 per cent, from less than 5 per cent as the previous ceiling (Mayer, 1999: 191). Given this appearance of the FN and the extreme right as a growing focus for identification, it seems crucial to assess the political bloc hypothesis in 1997 as well as in 1995. In particular, does the extreme-right group of identifiers manifest greater social and ideological specificity than before?

Our principal aims are two-fold: to establish whether the FN should now be separated from its moderate-right counterparts in a separate 
electoral bloc; and, second, to establish the extent to which the left-wing electorate has become more homogenous, in particular in ideological terms. More generally, we wish to assess the stability of support for the three alleged major political blocs - the moderate right, the left and the extreme right (essentially the $\mathrm{FN}$ ) - in order to discern whether there have been any trends in social realignment during the 1988 to 1997 period.

\section{Analysis}

We start with Table 11.2, which displays the demographic profile of the three major political blocs as determined by a survey question measuring party proximity. Here we can see clear differences in the socio-demographic profiles of the three major groups. A couple of general observations can be made from this table. First, the profile of extremeright identifiers is quite different from the profiles of moderate-right identifiers, but quite similar to the profile of left identifiers. Second, there has been very little change in the relationship between demographics and party proximity over time. We discuss these observations in more detail below.

TABLE 11.2 Demographic profiles (per cent) of party proximity groups in France (1988-97)

\begin{tabular}{|c|c|c|c|c|c|c|c|c|c|}
\hline & \multicolumn{3}{|c|}{ Left bloc } & \multicolumn{3}{|c|}{ Moderate-right bloc } & \multicolumn{3}{|c|}{ Extreme-right $(F N)$} \\
\hline & 1988 & 1995 & 1997 & 1988 & 1995 & 1997 & 1988 & 1995 & 1997 \\
\hline Men & 47.6 & 49.5 & 48.6 & 49.3 & 45.2 & 47.0 & 60.5 & 56.3 & 55.3 \\
\hline Less $\mathrm{t}$ & 8.2 & 23.8 & 21.0 & 17.6 & 21.0 & 20.0 & 32.2 & 39.3 & 26.7 \\
\hline Practi & 21.2 & 16.2 & 20.6 & 49.1 & 43.4 & 45.5 & 26.5 & 18.0 & 22.0 \\
\hline University deg & 15.1 & 24.8 & 21.0 & 18.2 & 23.8 & 23.7 & 11.8 & 15.8 & 7.3 \\
\hline \multicolumn{10}{|l|}{ Social class } \\
\hline $\begin{array}{l}\text { Managers and } \\
\text { professionals }\end{array}$ & 20.5 & 22.3 & 27.7 & 22.6 & 21.1 & 32.9 & 17.1 & 13.7 & 18.9 \\
\hline Self-e & 10.1 & 8.2 & 9.0 & 24.5 & 21.8 & 21.5 & 16.4 & 10.4 & 13.6 \\
\hline Rout & 30.3 & 21.7 & 29.1 & 26.3 & 19.8 & 22.9 & 24.3 & 26.8 & 25.0 \\
\hline & 39.1 & 47.8 & 34.2 & 26.7 & 37.2 & 22.7 & 42.1 & 49.2 & 42.4 \\
\hline Unemployed & 9.8 & 15.8 & 6.5 & 9.7 & 14.8 & 3.8 & 7.9 & 16.4 & 6.7 \\
\hline
\end{tabular}

We shall begin by discussing how the moderate-right profile differs from the profile from the other groups. Most importantly, we notice that moderate-right voters are generally older, more likely to be practising Catholics, have university degrees and be self-employed. The age differences are not surprising given that parties under the left bloc and the extreme-right bloc have clearly more radical policies. This concurs with 
previous research on voting and attitudes in western societies that shows young people are generally more likely to favour radical ideologies because they have less invested in the status quo. ${ }^{8}$

A similar explanation can be given for the overrepresentation of Catholics in the moderate-right bloc - i.e., since religious people are more likely to be socially conservative, they are also more likely to support the status quo and moderate parties. Differences in education and occupation can be explained by considering voters as rational actors who choose parties that best reflect their economic interests. This is especially true with respect to the fact that self-employed and educated people generally have much to gain from a well-functioning capitalist economy, something the moderate-right parties uphold more than others - looking at Table 11.2 , it equally applies to managers and professionals, two other groups served well by capitalist structures.

We now turn to an examination of the uniqueness of extreme-right support. Perhaps the most striking observation, albeit well documented in the literature, is the manner in which its gender profile stands out. Here we notice that the extreme right has clearly been far more attractive to men than women while both of the other blocs have slightly higher representation from women than men. Equally striking is the convergence of the party electorates across time: although men are still more strongly represented than women on the extreme right in 1997, the ratio has gradually moved towards parity since 1988. The opposite trend produces a similar effect in the moderate blocs. More at odds with 'accepted wisdom', however, is the finding that being unemployed is seemingly unrelated to party proximity and that this relationship changed little over time. Of course the marginal proportions of unemployed shifted across time, but the relative inter-group proportions remained fairly constant. Simply put, unemployed individuals are as likely to identify with the left or moderate right as the extreme right, ceteris paribus.

It is clear from Table 11.2 that the extreme-right and left groups find similarities in their attracting younger, less religious, working-class identifiers than the moderate right. This finding suggests that social divisions in the contemporary French electorate no longer can be divided neatly into the traditional bidimensional secular-working class and Catholicmiddle-class blocs. To what extent is there evidence of similar restructuring along ideological lines? Our analysis will now try to answer this question.

To assess changes in the cultural liberalism foundations of the bloc affiliations we can explore the relationships between party proximity and three types of issues: (a) authoritarian issues; (b) ethnocentric issues; and (c) sexual issues. Authoritarian issues are tapped by asking respondents whether they thought the death penalty should be reintroduced. This item was measured using a four-point scale with high scores representing 
FIGURE 11.1 Mean scores (standard deviations in parentheses) for attitudes in favour of immigration by party bloc

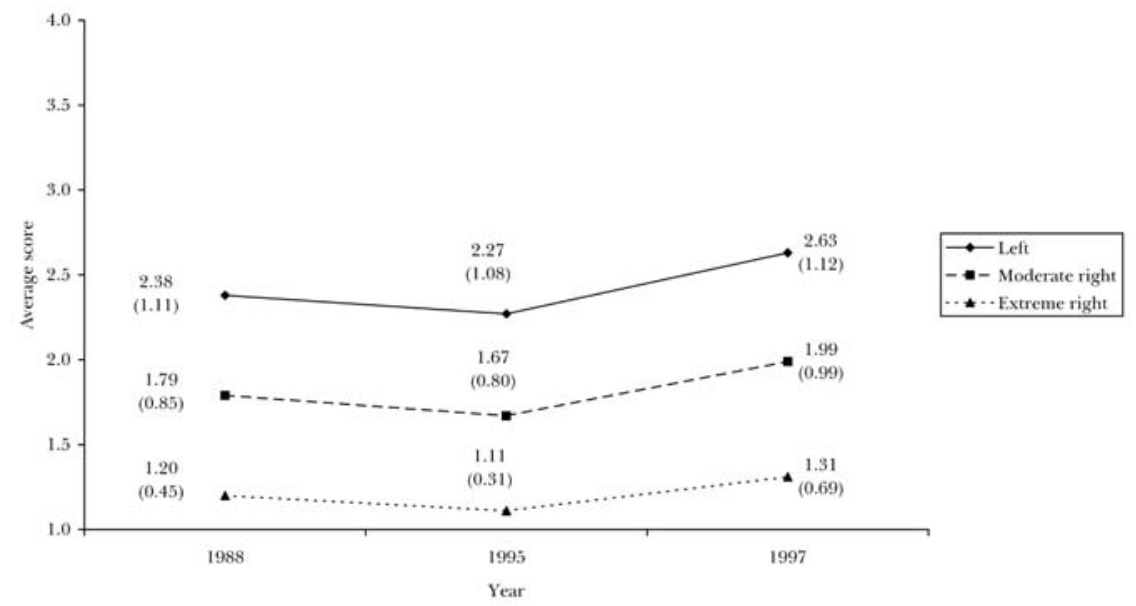

FIGURE 11.2 Mean scores (standard deviations in parentheses) for attitudes not in favour of the death penalty by party bloc

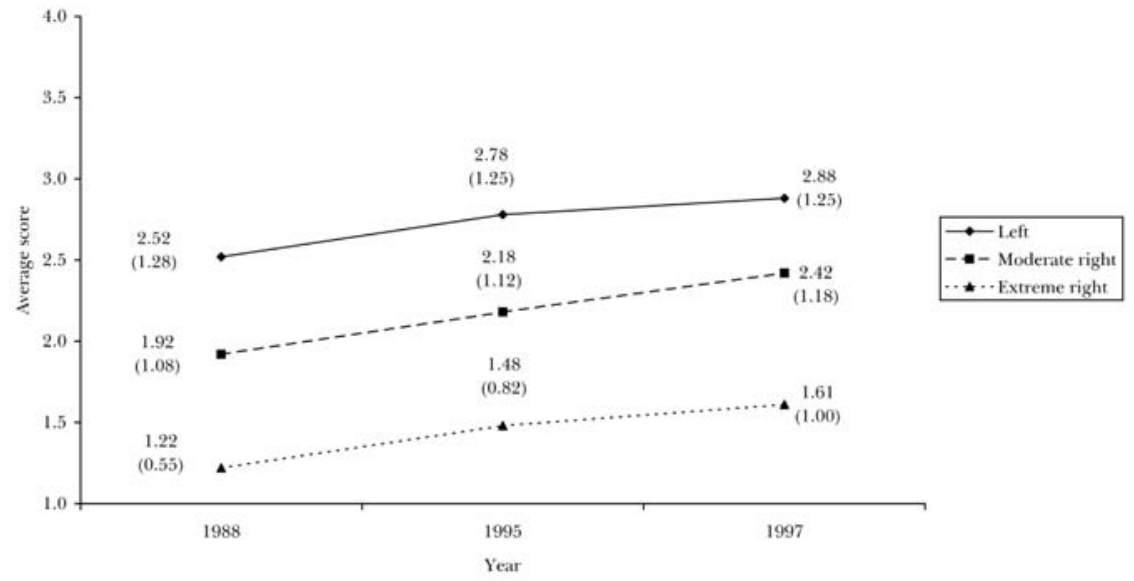

attitudes against reintroduction of the death penalty. Ethnocentric issues are tapped by a question asking how respondents felt about immigration. Low scores indicate that the respondent felt that there are too many immigrants in France while high values on this question represent disagreement with this statement. As we mentioned earlier, we only have data available for the homosexuality question pertaining to 1988 and 
FIGURE 11.3 Mean scores (standard deviations in parentheses) for attitudes against homosexuality by party bloc

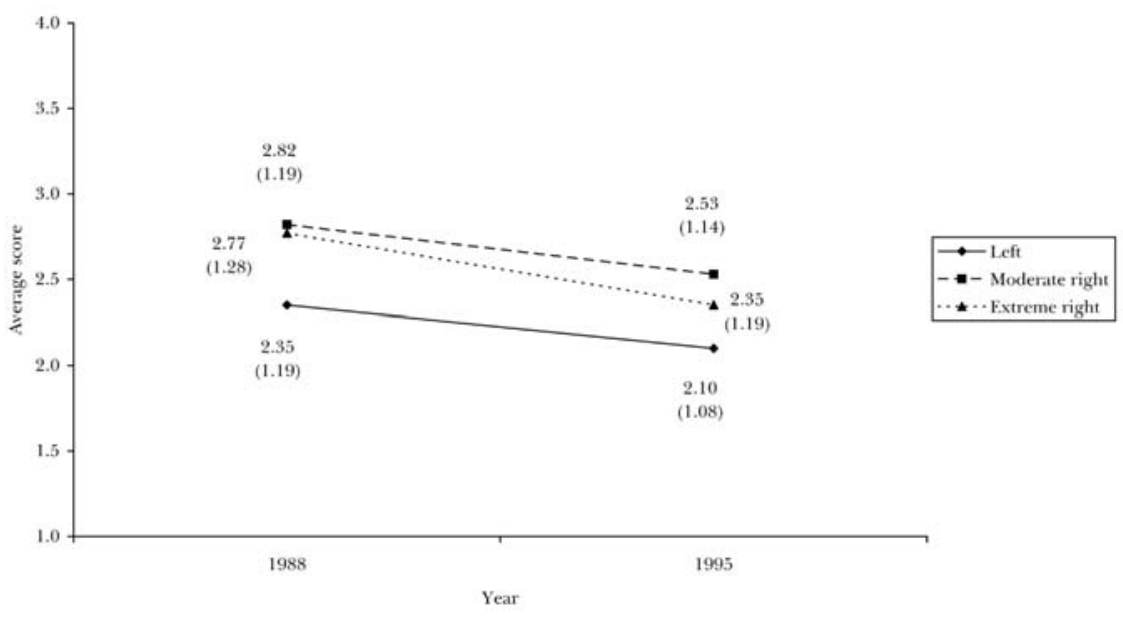

FIGURE 11.4 Mean scores (standard deviations in parentheses) for attitudes against privatisation by party bloc

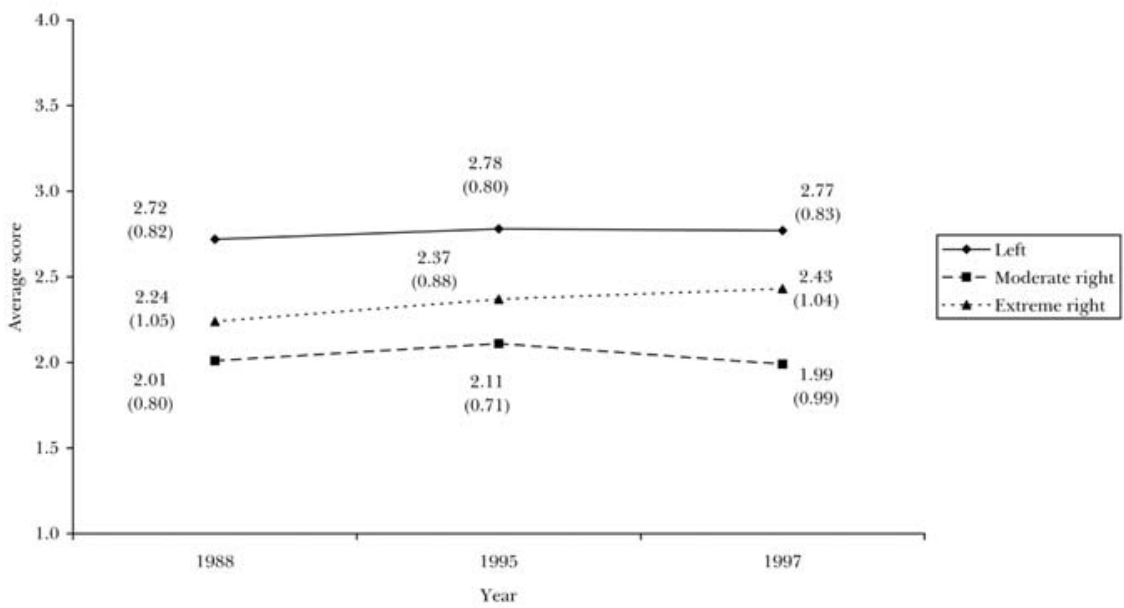

1995. The question in this case is coded so that high values represent attitudes against homosexuality.

The average scores (and standard deviations in parentheses) for the immigration and death penalty questions are shown in Figures 11.1 and 11.2. The most important point from these figures is that the profile of FN supporters is clearly on the extreme right of the political spectrum in all three years. On average, FN identifiers are far more likely to feel 
that there are too many immigrants in France and to desire a reintroduction of the death penalty than those who identify with the other two blocs. Concomitantly, left identifiers are far less likely to favour a reintroduction of the death penalty and far more likely to favour immigration than identifiers of the other blocs. With both of these issues the moderate right sits neatly between the FN and the left-bloc parties. Crucially, taking the score of 2.5 as the political centre, the moderate-right party consistently falls to the right of centre in all six cases. In other words, the moderate right resembles the extreme right in terms of direction but not in intensity. In this sense, the two blocs are not distinct.

We now turn to Figure 11.3, which charts attitudes toward homosexuality of the electorate for each of the major political blocs. Recall that high mean scores represent negative attitudes towards homosexuality. Looking at the trend between these, and expecting to see a drop in tolerance on the moderate right not matched by the extreme right, the prediction does not bear out. Very simply, the two parties move almost in parallel towards a slightly more tolerant stance. ${ }^{9}$ Regarding this issue, the moderate and extreme right both seem to be following the national trend towards liberalisation on such matters in 1995.

We now explore attitudes towards the economy. As stated earlier, Grunberg and Schweisguth argue that the FN could no longer be accommodated within the traditional left-right spectrum with regards to economic issues from 1995. Each of the surveys we use contained a question regarding attitudes toward privatisation which allow us to easily assess this argument. Figure 11.4 plots average responses to this question, with high scores indicating negative attitudes toward privatisation and low scores indicating positive scores toward privatisation, for each of the major political blocs. As Grunberg and Schweisguth suggest, we find that with respect to this issue, the FN's supporters are clearly in the centre between identifiers of the left and moderate-right bloc.

When examining the standard deviations of economic positions, however, we see that there was considerably more variation in mean scores for the extreme-right electorate than for the left and moderate-right electorates. Breaking down the figures by occupation, as in Table 11.3, it is evident that the lower social strata, represented by the blue-collar and routine non-manual occupations, are much less favourable towards privatisation than the managerial and the self-employed categories. The former strata are closer to the left bloc in their views, the latter to the right. Again, the benefits derived from free market capitalism determine the views of the individuals towards privatisation, and it would be unwise to see the electorate as having a single line on the subject. ${ }^{10}$

These findings for the right are again suggestive that political space in France is more than one dimensional - i.e., the left-right bloc does not neatly divide parties along a single dimension. Contrary to Grunberg 
TABLE 11.3 Average attitudes toward privatisation for extreme-right identifiers, by year and social class (standard deviations in parentheses)

\begin{tabular}{lccc}
\hline & 1988 & 1995 & 1997 \\
\hline Managers/professionals & $2.00(0.76)$ & $2.04(1.08)$ & $2.04(0.88)$ \\
Self-employed & $2.17(1.04)$ & $2.13(1.01)$ & $2.06(0.99)$ \\
Routine non-manual & $2.42(0.84)$ & $2.43(1.07)$ & $2.69(1.10)$ \\
\hline
\end{tabular}

and Schweisguth's argument, this pattern is stable through the course of the years we examine. This, of course, indicates that if there was a critical change in ideological space, it occurred before 1988 rather than in 1995. Moreover, the social profile of the $\mathrm{FN}$ is not distinctive, suggesting that there is not a clear basis for defining it as a distinct political bloc. ${ }^{11}$ There seems no ideological reason not to regard the $\mathrm{FN}$ as still on the radical wing of the right bloc in toto. Ultimately, the ideological disparities between moderate-right and extreme-right blocs are all a matter of intensity rather than direction.

Lastly, we return to the hypothesis of mass ideological convergence in the left bloc prior to the gauche plurielle incumbency. Simply, we find no support for this hypothesis. In all cases, the standard deviations remain constant, even in the cases where the position shifts across time. ${ }^{12}$ On cultural issues such as the death penalty and immigration, there is a shift between 1988 and 1997 towards a more liberal stance. Still, there is no evidence whatsoever of a mass convergence within the left bloc. Only with regards to homosexuality are opinions converging towards a more liberal position, but this shift is smaller than that of the right-wing electorate. Furthermore, in comparison with the two right blocs, there is greater disparity on the death penalty and immigration issues - to this extent, the evidence is that the left merits subdivision into more than one bloc as much as the right. Such figures demonstrate that the coalition-building was indeed based upon elite pragmatism, rather than any convergence of left-wing views.

Of course, it remains to be seen from the 2002 data whether or not the experience of cooperation has an effect at the mass level. As we have already noted, however, the electoral campaign and electoral results suggest that this was not the case. Granted, many of the problems with the left were associated with the campaign and its 'intended' candidate at the presidential ballottage, Lionel Jospin. However, the intense fragmentation on the left in the presidential first round and the almost entire inability of the gauche plurielle to field candidates under the hastily contrived gauche unie banner are clear indications that policy, as well as personality, were at stake. 


\section{Conclusion}

Overall, the key feature of French political space between 1988 and 1997 is its stability. While there are some trends in social and ideological profiles, these are subtle and do not indicate any major reconfiguration of the French electorate's views. In many ways, the left and the right blocs present interesting contrasts in this respect. The right, for so long fragmented by personality clashes, shows surprising evidence of homogeneity, even including the extreme right. The left, a coherent governing bloc between 1997 and 2002 because of elite compromise, shows no sign of ideological homogeneity, either empirically from its electorate's views in 1997 or speculatively from the 2002 election results. Moreover, those parties and candidates on the left trying to move the debate away from the traditional axis of competition, notably the MdC and Jean-Pierre Chevènement discussing the PRep, and the Greens pushing the environmental issues, both suffered in the legislative tally. To this extent, then, the left-right spectrum remains as valid as ever in French political life.

Most tellingly, perhaps, the 'nuisance effect' predicted to be devastating for the right in these elections ${ }^{13}$ turned out to be entirely redundant, despite Le Pen's earlier success in the presidential elections. Where the 37 triangulaires occurred, the $\mathrm{FN}$ experienced considerable losses as compared with the first round, undoubtedly because of a solid cohesive moderate right. The FN only made significant gains in straight two-candidate run-offs against the left, profiting from a proportion of moderate-right support. In other words, under both scenarios, the success of the extreme right is principally conditioned by the strength of the moderate right. The separate bloc winning support from both moderate blocs simply does not match reality in 2002 .

Indeed, the separation of moderate and extreme right as political blocs per se was already somewhat at odds with the experiences of the right over the past five years. First, the moderate right had itself experienced a level of fragmentation unprecedented under the Fifth Republic. While the basis to this has to a large extent been personality rather ideological politics at work, ideological differences are nonetheless present. As Evans has shown in his chapter on the European dimension (Chapter 10, this volume), some members of the UDF and of the former RPR are poles apart in their vision of France in the EU, even if there economic and cultural attitudes are close. The way the UDF can exploit this specificity in the new legislature will undoubtedly determine its survival over the next few years.

Similarly, one of the key issues in intra-UDF and UDF-RPR relations in the late 1990s - the regional council presidency support from the FN 
for the UDF - demonstrated diverse attitudes to relations with the extreme-right party. These feelings and conflicts were mutual - as Ivaldi has noted, one of the major sticking points between Mégret and Le Pen was precisely whether or not the FN should open to their moderate neighbours. These are all political divisions, undoubtedly, but again along the principal left-right axis, the ideologies remain similar in their direction, the socio-economic specificity of the two groups is blurred, and thus the 'third bloc' status of the FN/MNR and their presidential candidates is weak.

In conclusion, it is perhaps unsurprising to note that between 1988 and 1997, mass attitudes have changed little. After all, nine years does not represent a period sufficiently long to expect generational turnover in attitudes. However, it is clear that there has been no major sea-change in the French electorate's desires, either. Where political changes have occurred, it has been due to changes in political supply, either in shape or in quality. Indeed, it is quite revealing that the French electorate want pretty much what they wanted over a decade ago. However, from the continued alternation every election, a rise in protest voting and in abstention, they are simply still not getting what they want. That the left-right logic remains the principal axis of competition illustrates two things. First, the modern conceit that globalisation, Europe, post-industrial society and the rest are fundamentally altering the shape of politics does not find sustenance in political competition: as Cole states, these issues are undoubtedly muddying the ideological waters, but behind this the main ideological affiliations remain (see Chapter 1, this volume).

Second, and connected to this, the conceit that modern societies have solved the old conflicts that used to structure politics is also wrong. In an election campaign where the main differences between left and right parties appeared on issues of taxation and according to traditional left-right lines, the 'modern' issues have become a given for all parties rather than a new political cleavage and thus largely irrelevant in France's first-order elections. The search for something truly New in political competition continues.

\section{Notes}

The authors are indebted to the Banque de Données Socio-Politiques, Grenoble, for providing access to the 1988, 1995 and 1997 SOFRES/CEVIPOF post-election survey datasets and to CREST (Centre for Research into Elections and Social Trends) for providing funding for part of the research.

1 For ease of accessibility for readers, we refer throughout the text to the excellent translated version published by the University of Michigan Press (Boy and Mayer, 1993). 
2 On theories and interpretations of the post-industrial transformation, see in particular Dalton et al. (1984), Franklin et al. (1992).

3 On economic shifts on the extreme right, see Bastow (1997). On working-class voters moving to the extreme right, see Evans (2000a).

4 And indeed resigned once again, this time over the Corsican question.

5 Szarka is particularly vehement on this point, emphasising that 'the gauche plurielle represented an attempt to stabilise a crumbling electoral base, rather than a realignment of the French left' (1999: 35).

6 As Sauger recounts in this book, by 1999 DL had separated itself from the centre-right UDF, concerning itself with promoting the free market ethos (see Chapter 7).

7 Many observers have argued that party proximity/identification is traditionally weak in France (Converse and Dupeux, 1962, Percheron, 1977) but we concur with more recent literature suggesting that it has become sufficiently normalised in recent years (Converse and Pierce, 1986, Haegel, 1993).

8 On this, see for instance Inglehart (1990).

9 In fact, in a more robust testing of the tripartition hypothesis, the independent effect of the homosexuality issue on presidential voting and party proximity turned out to be stronger in distinguishing moderate right from extreme right in 1988 than in 1995. This element to the tripartition hypothesis would have been more suited to the earlier election, then - see Andersen and Evans (2003).

10 It is worthwhile acknowledging that the central position of the lower strata would be interpreted according to directional voting theory as ambivalence or indifference to the issue - see, e.g., Rabinowitz and Macdonald (1989), Merrill and Grofman (1999). Given blue-collar and lower white-collar defection to the FN and Le Pen through disillusionment with the moderate parties' competing but equally failing economic policies, such a lack of salience for this item would be unsurprising. In short, blue-collar and lower white-collar groups are not voting for the extreme right on the basis of economics.

11 We examine the theoretical role of socio-structural elements in political bloc definition in greater detail elsewhere (Andersen and Evans, 2003).

12 In the bloc codings, we realise that we have included two actors - the extreme left and GE - in the left bloc which are not included in the gauche plurielle government. The standard deviations remained almost identical when they were excluded from the left bloc, and so we have not excluded them for a separate analysis.

13 Le Monde, 2 February 2002. 
Robert Andersen and Jocelyn A. J. Evans - 9781526137746 Downloaded from manchesterhive.com at 04/26/2023 09:14:48AM 